$1-1-2015$

\title{
Bridging the Interdisciplinary Divide: Co- Advancing the Pedagogy of Environmental Justice Through a Digital Commons Initiative
}

Robin Evans-Agnew

University of Washington Tacoma, robagnew@uw.edu

Jane Compson

University of Washington Tacoma, jcompson@uw.edu

Chris Scott Lower

Follow this and additional works at: https://digitalcommons.tacoma.uw.edu/ias_pub

\section{Recommended Citation}

Evans-Agnew, Robin; Compson, Jane; and Lower, Chris Scott, "Bridging the Interdisciplinary Divide: Co-Advancing the Pedagogy of Environmental Justice Through a Digital Commons Initiative" (2015). SIAS Faculty Publications. 401.

https://digitalcommons.tacoma.uw.edu/ias_pub/401 


\title{
Bridging the interdisciplinary divide: co-advancing the pedagogy of environmental justice through a digital commons initiative
}

\author{
Robin Evans-Agnew* \\ Nursing and Healthcare Leadership, \\ University of Washington Tacoma, \\ Box 358421, 1900 Commerce Street, \\ Tacoma, Washington 98402, USA \\ Email: robagnew@uw.edu \\ *Corresponding author

\section{Jane Compson} \\ Interdisciplinary Arts and Sciences, \\ University of Washington Tacoma, \\ 1900 Commerce Street, Tacoma, \\ Washington 98402, USA \\ Email: jcompson@uw.edu
}

\section{Chris Scott Lower}

(Providence Regional Cancer System)

5109 41st Ave SE,

Lacey WA 98503, USA

Email: lowecs1@uw.edu

\begin{abstract}
Opportunities to advance environmental justice and sustainability pedagogy in academic settings are challenged by: 1) the balkanisation of such conceptions into different academic discourses, and 2) the exclusion of community discourses outside academia. Two dominant academic discourses in environmental justice originate from either anthropocentric (human) or ecocentric (non-human) conceptualisations. An interdisciplinary undergraduate teaching project that sought to integrate such discourses and privilege the voice of the community is described. In the course of an environmental ethics class, two faculty from philosophy and nursing initiated an assignment to produce short documentary interviews and transcripts $(n=18)$ with community members in a US City 'Defining environmental justice' for archiving as open-source material in a University Library. Of the video-transcripts produced, most $(n=16)$ explored anthropocentric positions. In this presentation, the dominance of anthropocentric discourses is explored as both an opportunity and a challenge for advancing the pedagogy of environmental justice and sustainability.
\end{abstract}

Keywords: environmental justice; sustainability; undergraduate education; ecocentrism; anthropocentrism; human health; deep ecology; USA; opensource; digital interviewing; community perspectives. 
Reference to this paper should be made as follows: Evans-Agnew, R., Compson, J. and Lower, C.S. (2015) 'Bridging the interdisciplinary divide: co-advancing the pedagogy of environmental justice through a digital commons initiative', Interdisciplinary Environmental Review, Vol. 16, Nos. 2/3/4, pp.158-174.

Biographical notes: Robin Evans-Agnew is currently an Assistant Professor at the University of Washington Tacoma Nursing and Healthcare Leadership program. His major interests are in the exploration of asthma inequities, environmental justice, and knowledge translation at the intersections of public health and primary care. His expertise is in community-based participatory research using critical discourse analysis and photovoice. He completed his bachelor of science in nursing at Johns Hopkins University in 1994 and completed his $\mathrm{PhD}$ dissertation research on asthma management disparity policy with African-American Adolescents and Public Health policymakers at the University of Washington School of Nursing in 2011.

Jane Compson is an Assistant Professor of philosophy and comparative religion in the Interdisciplinary Arts and Science program at the University of Washington at Tacoma. She teaches classes in applied ethics and comparative religion. Her research is on the application of ideas and practices from Buddhist traditions into contemporary contexts such as environmental ethics and healthcare. She has published in the journals Contemporary Buddhism, Mindfulness, and Religious Studies.

Chris Scott Lower is a Program Coordinator for the Integrative Cancer Care Program at Providence Regional Cancer System. His academic interests include environmental justice, micro-sustainability, and urban political ecology. During the Autumn of 2013, he completed a research project in India that explored how the development of local economies based on seed sharing can lead to improved socio-ecological resilience for rural farmers in the province of Dehradun. In 2014, he completed his bachelors of arts in sustainable urban development and environmental studies at the University of Washington Tacoma where he was a finalist for the Chancellor's Medal for Academic Excellence.

This paper is a revised and expanded version of a paper entitled 'Crossing the interdisciplinary divide: co-advancing workforce development in environmental justice through a digital commons initiative', presented at the Just Sustainability: Hope for the Commons, Seattle University, Washington USA, August 7-9, 2014.

\section{Manuscript body}

"Human justice is a fine goal, but it is not environmental justice. As even a cursory reading of the environmental justice literature suggests, the main concern of the environmental justice movement is humans. The nonhuman is only of interest insofar as it affects humans." (DeLuca, 2007, p.27)

This statement by environmental humanities scholar DeLuca (2007) succinctly encapsulates a tension in the field of environmental justice that we address in this paper, a tension that inspired the project that we describe here. This tension is between anthropocentric and ecocentric ways of valuing the environment and framing 
environmental justice. In his quote, DeLuca highlights anthropocentric ways of valuing the environment - the 'justice' is really about human justice, and the 'environmental' part is viewing the environment as the instrumental means through which this 'justice' can be expressed or denied. A more ecocentric conceptualisation, on the other hand, would recognise intrinsic value in the non-human, and recognise the need to promote ecosystemic health not just because of the effect on humans, but for its own sake.

Anthropocentric and ecocentric positions on environment, health, and humans are two dominant and divided academic discourses. In this paper, we sought to bridge this divide through an exploration of the community perspectives on environmental justice generated in an undergraduate digital commons (open source archived library material) interview assignment. This paper is organised to first provide a conceptual background on environmental justice and sustainability from our three academic disciplines of nursing, urban studies, and philosophy, then describe our digital commons video interview project and methodology we used for analysis. We next present the thematic topics we discovered, and discuss these in terms of challenges and opportunities for advancing the pedagogies of environmental justice and sustainability.

The three authors of this paper work in the same institution, but within different disciplines - one Assistant Professor in philosophy and religious studies, one Assistant Professor in nursing and healthcare leadership, and one undergraduate senior doublemajoring in environmental studies and urban studies. During informal conversations between us, we discovered that we all had a shared interest in environmental justice, yet each of our respective disciplines have varying conceptualisations of what the term means. From the perspective of nursing and healthcare, DeLuca's claim that "the nonhuman is only of interest insofar as it affects humans" seems fitting, as pollution and other forms of environmental degradation are seen as problematic insofar as they have deleterious effects on human health. This perspective is underscored by the World Health Organization's claim that "It is critical to ensure that economic and social policy responses to climate change and other environmental degradation take into account [human] health equity" (WHO Commission on the Social Determinants of Health, 2008, p.196).

A similarly anthropocentric approach is found in the discipline of urban studies. As an academic discipline, urban studies have traditionally focused on the complex and intertwining dynamics of human social relations, political processes, and economics that undergird metropolitan regions. While discussions of nature and the environment are embedded within the discipline, they typically focus on health risks such as pollution, and the management of stewarded areas such as parks. This has led to criticisms that urban studies as a field have failed to provide a holistic understanding of how the built and natural environments affect one another, thus perpetuating an anthropocentric perspective that the environment is strictly a resource for human utility and consumption (Hugentobler, 2006). Our institution has attempted to address this through novel pedagogical links with environmental studies, such as the inclusion of sustainability as an additional topic in the exploration of environmental justice (Agyeman, Bullard and Evans, 2002).

Ecocentric thinking is espoused within the area of environmental philosophy, where the anthropocentric approach is critiqued in favour of a more holistic understanding of human and non-human interrelatedness. There are multiple different philosophies in this category, but they tend to share a perception of the environment as having intrinsic value (value in its own right) as opposed to instrumental value (Katz and Oechsli, 1993). Yet, 
not enough is known how ecocentric thinking is being advanced, or how the divides between academic discourses are being bridged within the academic or the professional community. This is what we set out to explore in this study.

\section{Background}

The focus on human welfare as being the paramount concern relative to environmental justice arises from it being a social movement. Sauer (1999) contends the origins of this movement can be found in debates concerning European colonisation of North America, and the subsequent resource extraction from First People's lands. Others credit Carson's (1962) publication Silent Spring as sowing the seeds for the movement, calling for the need to take environmental control away from technocrats and privileged groups, and place it instead in the hands of local communities (Kroll, 2007). Another watershed moment occurred in 1978 when it was discovered that the Hooker chemical plant near Love Canal, New York, had been burying toxic chemical waste in makeshift landfills in and throughout the small community for decades. Such knowledge introduced a new concern about environmental issues, and of how environmental degradation can affect the well-being of human communities (Sirianni and Friedland, 2001). The event most often associated with the origination of the environmental justice movement, though, was the creation of - and subsequent protests about - a landfill to dump PCB-contaminated soil in Warren County, North Carolina, in 1982. The landfill was sited in an area that was poor, rural, and with a predominantly African-American population, and protests in this community drew national attention. This led to the arising of the environmental justice movement as distinct from the environmental movement generally.

In the 1980s, social activism became increasingly vested in championing environmental protections for disadvantaged, non-White neighbourhoods. In 1987, United Church of Christ's groundbreaking study Toxic Wastes and Race in the United States highlighted the disproportionate impacts non-Whites have suffered as a consequence of hazardous waste dumping across the USA (Middendorf et al., 2003). This report of inequalities echoed the research of sociologist Bullard (1983) whose work in the 1970s showed that landfills in Houston, Texas, were far more likely to be located near African-American communities than white neighbourhoods. As a consequence of these events, grassroots groups dedicated to resolving socio-environmental inequities have been growing in increasing numbers with environmental justice becoming a popular term among activist, political, and scholarly circles concerned with human health and inequities.

Since its beginning the environmental justice movement, building on the foundations of the environmental movement has helped catalyse a growing body of legal and regulatory protections to include the Toxic Substances Control Act, the Safe Drinking Water Act, and the Asbestos School Hazard Act, as well as site remediation programs such as Superfund (Agyeman and Evans, 2003). As a means of defining and pursuing justice, the movement has emphasised fairness and equity, meaning all people regardless of ethnicity or socioeconomic status should be given equal concern and respect relative to the disposal of toxic waste and siting of industrial operations (Jones, 2009). This linkage of equality-based justice to regulatory solutions has worked to entwine modern discourses concerning environmental justice around two primary thrusts: one, that all 
people are entitled to fair and equitable treatment in regard to the regulation, implementation, and enforcement of environmental protections (US Environmental Protection Agency, 2014); and two, that all people are entitled to an equitable share of ecosystem services, as well as equal access to natural spaces (De Chiro, 1996).

The disciplines of urban and environmental studies draw frequently from the history of the environmental justice movement, particularly as it applies to understanding how unequal power relations, ecological decline, and inadequate municipal planning coalesce to create socio-environmental inequities both domestically and abroad. Pedagogically, this has meant modelling environmental justice coursework around topics of human rights and governmental protections where the former are presented in terms of equity and fair access, and the latter in terms of regulatory measures (Washington and Strong, 1996). As an interdisciplinary discipline, environmental studies have traditionally attempted to fuse ecological and biological topics with the social sciences, making it an ideal platform for exploring issues of environmental philosophy and justice (Soule and Press, 1998). Like urban planning, environmental studies view environmental justice through a lens of human equity and fairness, emphasising regulatory and social mechanisms capable of achieving these goals.

Within the pedagogy of nursing science, the origins of environmental health nursing began with the observations and actions of Nightingale in 1855 to improve indoor air quality in the hospital stations in the Crimea (Nightingale, 1970). During the last 50 years, nursing perspectives on the environment have split into two streams, being either viewed as an epidemiological issue or as a foundational element of human health. It has only been since the early 1990s that nursing began to see environmental advocacy and environmental justice as essential tools of nursing, such as addressing nuclear waste (Clark et al., 2002). In nursing and healthcare research, concern for environmental justice has grown over the last decade. Discussions have centred on the impacts of the environment and environmental degradation on human health (Chircop, 2008; Wilson, 2009; Morello-Frosch and Lopez, 2006). Greater attention in US nursing is focused on how environmental justice relates to evidence of health disparities between groups of people who are more or less disadvantaged with an emphasis on examining the lives of the disadvantaged (Bullock, 2008; Krieger, 2005; Braveman, 2006).

It is notable that urban studies, nursing science, and environmental studies all have similar approaches to how environmental justice is taught, meaning all three emphasise human-based justice and social constructs such as politics, laws, and regulations. This emphasis on human needs above all other considerations is characteristic of an anthropocentric worldview, and echoes the environmental justice movement's central theme that human well-being is of the utmost importance. Anthropocentric models for teaching environmental justice have been challenged in recent years, however, by the discipline of philosophy that has embraced a new field of environmental ethics that explores the moral implications of including concerns for non-human beings and ecosystems. As a concept, environmental ethics was inspired by the first Earth Day in 1970, along with such seminal writings as Lynn White's “The Historical Roots of our Ecological Crisis" (White, 1967) and Aldo Leopold's "Sand County Almanac" (Leopold, 1949). Environmental ethics is now a rapidly growing field, and works on the premise that the roots of our ecological crisis are philosophical. In other words, our foundational value assumptions influence our behaviour, and a prerequisite for changing our behaviour is changing the values that underlie them. These ecocentric critiques of anthropocentrism also come from indigenous cultures and take many forms within Western philosophies 
such as Deep Ecology (Sessions, 1995), the Gaia hypothesis (Lovelock, 2000), and ecofeminism (Warren, 1997). Although diverse, these philosophies share a common thread that the problem with anthropocentric ethics is that it is based on a misconception of reality that sees humans as ontologically separate and somehow superior to the rest of nature. Anthropocentric conceptions of environmental justice will be ineffective and inadequate as long as they ignore our biological rootedness and dependence on the ecosystem because the underlying philosophy that sees people as being apart from, rather than a part of, the ecosystem predisposes people towards environmentally insensitive behaviours.

There have also been critiques of environmentalism as promoting injustice towards human beings, particularly the poor, in both the global North and South (Wenz, 2007), by favouring preservation of the environment in ways that are detrimental to the welfare of poor and disenfranchised humans. In response, some ecocentric philosophies explicitly challenge the conceptual distinction between social justice and ecological ethics, arguing that an ecocentric philosophy promotes, rather than competes with, human social justice. In other words, when it is recognised that humans are part of, not apart from, the ecosystem, then improvement in eco-systemic health will necessarily benefit human health. Furthermore, just as a 'logic of domination' (Warren, 1997) leads to social injustices against humans, so these same ways of thinking result in harms to the ecosystem.

White, for example, famously blames the Christian Old Testament idea of humans having dominion over nature as being at the root of our ecologic crisis:

\section{"Despite Darwin, we are not in our hearts, part of the natural process. We are superior to nature, contemptuous of it, willing to use it for our slightest whim." (White, 1967, p.23)}

White expressed great skepticism about the likelihood of success of scientific or technological attempts to address the ecological crisis as long as they are rooted in this anthropocentric philosophy: "Unless we think about fundamentals, our specific measures may produce new backlashes more serious than those they are designed to remedy." (White, 1967, p.219).

In his Land Ethic, Leopold addresses such fundamentals. He argues that all ethics is based on "the single premise that the individual is a member of a community of interdependent parts" (Leopold, 1966, p.375), but argues that humans have neglected to consider themselves as members of an ecological community, and have played the role of conqueror over biotic community. He calls for an 'extension of ethics' to include "soils, waters, plants, and animals, or collectively: the land" and suggests that this reconceptualisation will entail a new respect for the biotic community: "In short, the land ethic changes the role of Homo sapiens from conqueror of the land-community to plain member and citizen of it." (Leopold, 1966, p.375).

Here, we see clearly the focus on attitudinal changes as a necessary condition for behavioural changes. Leopold argues that it is not just our conceptualisation of the role of humans in the ecosystem that must change, but also our emotional sense of connectedness: "No important change in ethics was ever accomplished without an internal change in our intellectual emphasis, loyalties, affections and convictions." (Leopold, 1966, p.377)

This conceptual shift in affections and convictions rests on an understanding of our dependence on the ecosystem. One of the philosophers who brought environmental ethics to the attention of mainstream philosophy, Holmes Rolston, argues that the "old 
paradigm" of ethics relies too strongly on 'anthropic values' such as rights and the existence of pleasure and pain. Non-human animals are only included in the circle of moral concern insofar as they are "like us": "Justice remains a concern for just-us subjects." (Rolston, 1991, p.75). The new paradigm, argues Rolston, must "move past a hedonistic, humanistic logic to a bio-logic" (p.76). In other words, like Leopold, he argues that we should consider the health and integrity of the ecosystem in our moral valuations.

Proposed paradigm shifts like this clearly offer pedagogical challenges, and have inspired some calls for new models of teaching that encourage students to explore and nurture students' sense of loyalties and affections for the non-human world. For example, Zajonc (2006) calls for the integration of contemplative techniques into the academic classroom to help foster an "epistemology of love" rather than an "epistemology of separation." Orr (2004, p.14) argues that in our education systems "we ought not look first to our technological cleverness or abstractions ... but rather to the extent and depth of our affections which set boundaries on what we do..."

One of the challenges of teaching philosophy is that the focus on theoretical abstractions can lead to a neglect of praxis, of seeing how the theories are applied in practice. One of our intentions in the digital commons project we describe in this paper was to give students the opportunity to discover for themselves how anthropocentric or ecocentric discourses manifest in voices from the local community. We hoped to offer students a practical and contemporary example of how discourses are value-laden, even if those who espouse them do not explicitly recognise these values.

To sum up, we have briefly sketched the distinction between anthropocentric and ecocentric conceptions of environmental justice. We have described how within our respective disciplines, anthropocentric discourses seem to dominate in the nursing, urban studies, and environmental studies, whereas the ecocentric perspective was much more in evidence within environmental philosophy. Responding to the expressed urgency to transform anthropocentric ways of thinking in favour of ecocentrism, we became curious about this conceptual divide between our academic discourses, and also how they might correspond to conceptions of environmental justice outside academia. We were also keen to involve students in this exploration, so we devised a student project to implement in our classes, and were funded in our efforts by an institutional grant.

\section{Methods}

The class we chose was an upper-division environmental ethics class taught in Fall 2013. Of the 39 students enrolled, a variety of majors were represented, reflecting the emphasis on interdisciplinary knowledge development in our institution. As part of a class assignment, we required the students to identify, recruit, edit, and transcribe a video interview with a community stakeholder discussing the definition of environmental justice. These videos were edited to be less than 15 minutes long and were uploaded to a YouTube site. Students identified community members with a stakeholder interest in the environment from both the campus and local community through a variety of contacts provided by us and other personal connections. Our institution is an urban-serving campus, and with that in mind, students were encouraged to pursue their own connections within the university and in the wider community; the requirement was that their interviewee must have some professional interest in issues relevant to environmental 
justice. Students and interviewees signed consent forms to participate and were informed about the publishing of the interviews on a public 'digital commons' web-location in the University Library. Students conducted the interviews using an open-ended questioning strategy that used following questions (and prompts in parenthesis):

1 What is environmental justice?

2 How does/doesn't environmental justice work in your community (What needs to change?),

3 What parts of environmental justice are important to you (Why, why not?),

4 How does concern for the environment fit with other environmental justice concerns (Such as sustainability, health, or nature?),

5 In your opinion, how is environmental justice useful to you in addressing the issues in your community (How might others be able to help?).

About half of the students were environmental science students, and the rest were from a diverse collection of majors: environmental studies; criminal justice; social work; nursing; arts, media, and culture; politics, philosophy, and economics; computer science; informatics; communication; and sustainability and urban design. Students worked in teams of two or three to make the interviews. In the end, we had 18 interviews (Table 1) representing a diversity of professional backgrounds from the Puget Sound Area including University faculty from environmental science and urban studies $(n=6)$ nonprofits $(n=4)$, businesses $(n=1)$, state and local elected officials $(n=2)$, and government agencies $(n=5)$.

Table 1 Interviewee demographics and background

\begin{tabular}{lc}
\hline Interviewee & Number $(\%)$ \\
\hline Female & $10(56 \%)$ \\
Male & $8(44 \%)$ \\
Total & $18(100 \%)$ \\
University faculty-environmental science & $3(17 \%)$ \\
University faculty-urban studies & $3(17 \%)$ \\
Governmental agency & $5(28 \%)$ \\
Elected officials & $2(11 \%)$ \\
Non-Profit & $4(22 \%)$ \\
For profit business & $1(6 \%)$ \\
Total & $18(100 \%)$ \\
\hline
\end{tabular}

The video-interviews were collected at the end of the course, and along with the transcripts, made available through our institution's Library Digital Commons open source site (http://digitalcommons.tacoma.uw.edu/ej_interviews/). We created abstracts of all the interviews and made them available on the digital commons site. 


\section{Analysis}

Of the participant interviews, participant texts $(n=18)$ were grouped into 15 thematic topics that included discussions concerning ecocentric $(n=8$ texts) and anthropocentric ( $n=16$ texts) ways of thinking and that identified topics concerning environmental degradation ( $n=9$ texts) (Table 2 ). We found that participant texts sometimes included both anthropocentric and ecocentric conceptualisations. The analysis process utilised deductive content analysis (Elo and Kyngäs, 2008; Hsieh and Shannon, 2005) to identify thematic topics for ecocentric and anthropocentric ways of talking amongst participant interviewees. The analysis process was conducted with two members of our writing team each by completing the following steps:

1 clarification of concepts and summary of dominant thematic topics

2 identification of the breadth of thematic topics

3 collapsing thematic topics and extraction of exemplar quotes. These processes are explained in more detail below.

In the first round, we identified the dominant concepts of anthropocentric and ecocentric ways of thinking. We identified topics within the texts that seemed to not be clearly either anthropocentric or ecocentric, but that contested this dichotomy. We also identified some key quotes that exemplified both dominant concepts. At the end of this round, we reconceptualised ecocentric thinking as being inclusive of anthropocentric thinking and we identified 'environmental degradation' as a third concept in the interview texts.

In the second round of analysis, we re-read all the texts, identified, and detailed thematic-topics for each of our main concepts. We wrote out and posted these thematic topics onto butcher paper and began to organise them through a pile sorting technique. We then collapsed these thematic topics into the dominant concepts of anthropocentric, ecocentric, and environmental degradation. We included references to specific words and quotes used in the texts that exemplified these thematic topics. The last and final round of analysis involved pulling these quotes and determining whether some themes could be collapsed further. We made a note of how many unique participant interviews contained these thematic-topics.

\subsection{Results}

Of the participant interviews $(n=18)$, participant texts were grouped into 13 thematic topics that concerned ecocentric $(n=9)$ and anthropocentric $(n=16)$ ways of thinking and those that identified topics concerning environmental degradation $(n=9)$ (Table 2$)$. We found that participant texts sometimes included both anthropocentric and ecocentric ways of talking about environmental justice. The themes are described in detail below. 
Table 2 Interview texts that contained anthropocentric, ecocentric, and environmental degradation themes

\begin{tabular}{ll}
\hline Theme (number of topics) & Thematic topics (interviews that included them: $n=18$ ) \\
\hline Ecocentric (six topics) & $\begin{array}{l}\text { Interrelatedness with the non-human other, notions of frugality, } \\
\text { holism, elitism versus interrelatedness, the value of non-human } \\
\text { health, and the value of everyday environments }(n=8)\end{array}$ \\
$\begin{array}{l}\text { Anthropocentric (three topics) } \\
\begin{array}{l}\text { Environmental degradation } \\
\text { (four topics) }\end{array}\end{array}$ & $\begin{array}{l}\text { Air and water pollution, food access, non-pollution sources, and } \\
\text { global warming }(n=9)\end{array}$ \\
\hline
\end{tabular}

\subsection{Anthropocentric ways of thinking}

Overall, most $(n=16)$ participants utilised anthropocentric ways of talking about environmental justice. Participants used three thematic topics for such anthropocentric conceptualisations: sustainability, economics, and human rights.

Some participants discussed sustainability in terms of being concerned about "shift[ing] away from burning fossil fuels, that's going to help a lot of things. That's sustainability, that's health, warming planet, you know we're seeing diseases that we didn't used to see." Another participant talked about sustainability in terms of mitigating human impact by "allowing the environment the time to recover from our use." Other participants related sustainability to stewardship: "so when we act as good stewards of the environment, what we're doing in a sense is making sure that those natural resources will remain in perpetuity for our community."

Anthropocentric ways of talking included many interviewees discussing economic concerns. These concerns related to economic concerns in general $(n=3)$ such as improving the environment "will also save residents money" and provide "economic prosperity" or putting a monetary value on "ecological economics" for the improvement of the environment and the economic value of the "shade of a tree." Additionally, participants talked about the impacts of corporate economic power in environmental justice. One participant described the "large powerful corporations who modify our food" and another talked about the need for "political clout that we need to counter businesses and industries that are really working to keep us from improving our water quality..." Others argued for the important consideration of the burden of the 'external costs' of automobile pollution.

Other economic concerns related to politics and the importance of having elected officials "actually consider who is talking to them and whether that's really a response from the community as a whole, or whether it's one particular really powerful group." In addition, some participants thought that political mobilisation was very important for "people to really get behind."

Some participants also identified the importance of economics in relation to the use of 'environmental resources' to make the environment 'safe and productive.' This perspective included the idea of "making sure that those natural resources will remain in perpetuity for our community." This concern for human action to protect and preserve resources was also present in participants' discussion of "being a good steward of the 
environment" in concert with the economic interest to "regulate things that should be regulated and need to be regulated, but can't regulate themselves."

Another way participants had of thinking about economic concerns in relation to environmental justice were in discussions of 'social issues' such as economic, racial, and gender inequity. For example, participants discussed "institutional racism, institutional sexism, that we don't often see and don't pay attention to because they are so insidious in our everyday lives" and the importance of "social politics to improve how we relate to each other." Another participant positioned the talk about environmental justice and equity in terms of privilege: "It requires that we think about what are environmental privileges and how can we live in a way that shares those privileges and does not put unnecessary burdens on others." Lastly, participants acknowledged that these economic issues were structural, and that the work of environmental justice was to:

“... identify patterns of structural inequity and structural racism that are associated with the siting of these burdens here, predominantly low income communities, which also are frequently communities of colour."

The last anthropocentric thematic topic introduced by participants was in relation to human rights. Participants discussed the importance of engaging the 'voice' of marginalised communities to "not accept the way things are" but to "tell their story to elected officials" and to have those in power 'listen' to them. Participants reflected on how it was their responsibility "to help people have those tools and the confidence to be able to speak up for themselves and their community and giving them the security that there will not be negative repercussions." Some participants emphasised the right to education for these communities, for example, to learn 'skill sets' for urban gardening, or to become more 'aware.' Lastly, participants talked about the right of having "equal access to things that we need" such as 'green space' and 'food.'

\subsection{Ecocentric ways of thinking}

Participants $(n=8)$ used six thematic topics for ecocentric conceptualisations: interrelatedness with the non-human other; notions of frugality; holism; elitism versus interrelatedness; the value of non-human health; and the value of everyday environments. These thematic topics are described next.

Participants often described a core theme of interrelatedness, 'integration,' or 'interdependence' in relation to environmental justice, acknowledging that 'non-human,' and 'complex' processes of the 'ecological system' were equally important: "I think environmental justice does help us recognise the complexity of each situation where we might need to reconsider the most appropriate kind of plant life is in that area to accommodate both humans and nonhumans."

Some participants addressed consumerism with the idea of being 'frugal' or 'giving up' things in order to be less 'self-serving.' For example, one participant suggested that society needed to be more focused on how "to be more frugal; we have to adapt our technology as well to be as efficient as possible because efficiency is also such a big part of the problem."

One participant talked about the importance of the "holistic sense of the term environment" and a concern for non-human health. In addition, one participant pointedly identified the difference between environmental elitism and a more holistic and connected sense of the environment: 


\begin{abstract}
"Some environmentalists go really far in the ecocentric direction, some environmental justice groups go really far in the anthropocentric, some polarization of the dialog, and I think finding a happy middle ground is really important."
\end{abstract}

Another participant talked about valuing the more mundane and ordinary aspects of "nearby nature" rather than exotic environments far from urban areas.

\title{
4.4 Ways of thinking about environmental degradation
}

Some participants $(n=9)$ clearly identified four thematic topics for environmental degradation in relation to environmental justice: air and water pollution, food access, non-pollution sources, and global warming. Participants described environmental degradation in relation to air and water sources such as 'indoor environments,' 'wood burning stoves,' and "our waters are unsafe to fish in." Other participants discussed food access and other nutritional access issues such as eating "contaminated fish" by people who use "traditional fishing... who may not be able to access cleaner areas," and just 'unhealthy nutrition.' Non-polluting sources of environmental degradation were suggested by some participants such as "where things get sited and who gets impacted" such as the locations of schools next to freeways, and access to transportation and "walkable communities." Lastly, one participant identified the 'warming planet' as an environmental justice issue because: "we're seeing diseases that we didn't used to see, we're seeing storms that are much more extreme or more frequent than we've ever seen before."

\section{Discussion}

More than half of the participants for this study were from outside the university community. Participants were evenly divided between males and females and represented professional concerns for environmental justice, either in their research or occupations. However, it is interesting that although the students did not interview any faculty or community members involved in the healthcare sector specifically, there was an abundance of anthropocentric thinking amongst interviewees.

We found that anthropocentric ways of thinking predominated interviewee texts with concerns for human actions in relation to economics and human rights. We found that it became easier to identify anthropocentric conceptualisations by looking for phrases and sentences relating to humans and to human actions that must be taken to mitigate or regulate the environment. In comparison, we found it hard to identify ecocentric conceptualisations using the looser concept of 'interrelatedness.' This finding is consistent with national discourses of environmental justice coming from definitions utilised in the federal government and elsewhere (US Environmental Protection Agency, 2014). These national definitions utilise human-centred ways of talking and limit nonhuman concerns. Indeed, the concept of 'justice' is itself a socially constructed act, which may further encourage the predominance of anthropocentric discourses.

Environmental degradation as a theme was likewise tied to anthropocentric thinking as interviewees discussed the impact of air pollution and other forms of industrial waste are having on human health and neighbourhoods. An interesting example emerged during discussions on how waterborne pollutants in Puget Sound are bio-accumulating in 
populations of edible fish, thus endangering groups of people dependent upon these species for subsistence fishing. What is salient here is that the respondents engaging with this topic did so only in terms of human health, and did not reference the poisoning of aquatic species as being a concern for the ecosystem separate from human consideration.

Conversely, ecocentric ways of talking were emergent in interviewee texts but less explicit and nuanced than anthropocentric ways of talking. For example, human concerns regarding economic values were well described, but participants did not explore in-depth ideas relating to ecosystem health. As such, the evidence from these texts suggest that participants were not orientated towards non-human interests.

One of the things we noticed when comparing anthropocentric and ecocentric statements from the interviewees was that when people made ecocentric statements, they tended to make allusions to undergirding philosophies, such as holism or interdependence. In contrast, the philosophical underpinnings of the anthropocentric statements were not explicitly mentioned and remained unacknowledged. We hypothesise that this is because anthropocentric ways of thinking represent the status quo, and the foundational values underlying them are assumed and generally unchallenged.

One challenge worthy of future discussion surrounds the issue of "environmental elitism" as another form of social injustice. For example, the "Group of Ten' leading environmental organisations have been criticised by environmental justice activists of marginalising the interests of people of colour, the poor, and perpetuating systemic injustice by advocating for environmental policies that place disproportionate burdens on underprivileged groups (DeLuca, 2007; Wenz, 2007). Such discussions may provide excellent pedagogical opportunities for students to explore potential conflicts between diverse perspectives and ways of knowing.

Our findings provide opportunities for expanding the conceptual underpinnings of environmental justice to expand ecocentrism-focused pedagogy. Clearly, ecocentric understandings of environmental justice are emergent in our interview population, but as we suggest, ecocentric forms of discourse can be thought of as inclusive of existing anthropocentric ways of thinking. As such, an opportunity exists within environmental justice pedagogy to more deeply explore many of the themes central to anthropocentric ways of thinking that can cross over to ecocentric ways of thinking such as the thematic topics of sustainability and environmental degradation. Indeed, such topics could anchor an ecocentric pedagogy. For example, most theoretical models of sustainability focus on human-centred ideas of ecological stewardship, social equity, and economic vitality (Saha and Paterson, 2008); and yet the roots of sustainability are just now being recognised in our respective disciplines as being connected to the ecocentric values of holism, as evidenced by concerns over climate change increasingly expanding to include the entire biosphere rather than solely referencing human health (Anaker and Elf, 2014). Similarly, in addressing the roots of environmental degradation, a nursing professor might encourage students to grapple with "the underlying dominant motives that are in play in society; motives which are inherent in our most fundamental ways of thinking about ourselves and the world" (Bonnett, 2002, p.19). For example, the pedagogical act of engaging nursing students in an environmental restoration project might provide an opportunity for deeper reflection as to the healing of the social values that led to such degradation.

Another opportunity exists in the use of language to expand ecocentric ways of thinking within anthropocentric discourses. For example, participant use of the term 'ecosystem services' could be considered to be a less anthropocentric term when 
compared to concepts that seek to place economic value on such natural processes as pollination or waste decomposition. Ecologists popularised the concept of ecosystem services in the 1990s. They sought to describe the various benefits conferred to human society by nature: provisioning (e.g. food and timber), regulating (climate and decomposition), supporting $\left(\mathrm{O}_{2}\right.$ production through photosynthesis), and cultural (recreational opportunities) (Daily, 1997). Yet, despite its moorings in human utility and, therefore, anthropocentrism, the concept of ecosystem services does allow for a consideration of the integrity of such ecosystems in and of themselves as described in the World Charter for Nature, “...resources which are utilised by man shall be managed to achieve and maintain optimum sustainable productivity, but not in such a way as to endanger the integrity of those other ecosystems or species with which they coexist" (United Nations, 1982, p.2).

Another way ecocentric thinking can be expanded is relative to the contestation of 'structural inequities' which was a term participants used to describe the institutionalised power differentials contributive to environmental injustice. On the surface, structural inequity is a uniquely anthropocentric idea, and refers to the power hierarchies responsible for perpetuating the unequal and discriminatory siting of toxic waste and industrial operations proximal to minority communities and the poor. It is important to remember, though, that such power hierarchies are embedded in dualistic thinking where groups are split into disjunctive pairs, such as rich-poor or nature-culture, which are then used to justify the superiority of one over another (Warren, 1997; Naess, 1973).

In using ecocentric thinking, we can challenge dualistic thinking by expounding on the idea of 'interrelatedness' which rejects dualisms by ascribing equal worth to all beings living within a system. By replacing dualistic thinking with an appreciation for the interrelatedness of all living things and people, we can also contest structural inequities in health by teaching others how diversity is not just a cornerstone for healthy ecosystems, but also for human communities. Importantly, 'interrelatedness' is a concept fundamental to principles of diversity and was one of the most common ecocentric terms used by our participants.

This project demonstrated an innovative way to privilege the voice of non-academics inside an academic setting. By making the production of this voice be a part of a classroom assignment, students were engaged in a tangible activity that engaged with an important set of professional stakeholders. The success of this activity suggests that further development of this digital commons repository could further strengthen our own teaching and research on environmental justice and sustainability.

This study also shows that community oriented digital commons projects on environmental justice and sustainability can benefit students, faculty, and community members. The benefit for students is the generation of contemporary and 'living' texts that deal with the content of the class. The benefits for faculty are in the unification of varying disciplines and the expansion sustainability-based coursework that engages students in anthropocentric and ecocentric thinking. The benefit for community members in having access to other stakeholder interviews is in the deepening of knowledge of the values underlying environmental justice and sustainability. Such projects would also advance the concepts of environmental justice by encouraging all to engage in a broader, less anthropocentric understanding of sustainability.

There are some limitations to this project. First, the interviews collected represent a very small slice of environmental justice opinion in one local community and are not 
generalisable. Second, since this project was a pedagogical experiment, student-generated texts were of very mixed quality reflecting varying levels of ability and motivation in the group. Third, while in our questioning strategy, we took care to not use words that would predispose people to think only in terms of human health, we did include words like 'community' which may have predisposed interviewees and interviewers to conceptualise this in terms of human communities. While important, these limitations point to the need for further application and exploration of environmental justice through community engagement. Our project gives a pedagogical example of how this might be achieved.

\section{Conclusion}

The experience of conducting this project has illuminated the complexities of advancing a conceptualisation of environmental justice that can cut across the interdisciplinary and conceptual divides between anthropocentric and ecocentric ways of thinking. To adequately prepare undergraduate students who are concerned with environmental issues, we have shown that we must engage in more complex and integrative ways of thinking and talking about the environment than to simply produce perspectives from imagined positions at either side of the debate. As one interview participant suggested, "I think environmental justice does help us recognise the complexity of each situation where we might need to reconsider the most appropriate kind of plant life is in that area to accommodate both humans and nonhuman."

In this paper, we have described an innovative approach to advancing the pedagogy of environmental justice across the academic discourses of urban studies, nursing, and environmental ethics. Utilising student-produced, transcribed, and open-source-published interviews with community members that explore unique perspectives on environmental justice, we have been able to identify important challenges and opportunities for integrating and extending anthropocentric and ecocentric conceptualisations. In addition, we have begun to consider how the advancement of such conceptualisations might lead to new pedagogies concerning environmental justice and sustainability that are more interrelated within our disciplines. While this project has illustrated there are strong undercurrents on discourses that continue to divide our ways of thinking, our academies themselves may be less divided than we originally thought. Indeed the urgency to advance our pedagogy may lie in our shared interests in limiting environmental degradation, in deepening our values with regard to human and non-human health, and in extending our commitment to justice and equity towards the ecosystem as a whole.

\section{References}

Agyeman, J., Bullard, R. and Evans, B. (2002) 'Exploring the nexus: bringing together sustainability, environmental justice, and equity', Space and Polity, Vol. 6, No. 1, pp.77-90.

Agyeman, J. and Evans, T. (2003) 'Toward just sustainability in urban communities: building equity rights with sustainable solutions', The Annals of the American Academy of Political and Social Sciences, Vol. 590, No. 1, pp.35-53.

Anaker, A. and Elf, M. (2014) 'Sustainability in nursing: a concept analysis', Scandinavian Journal of Caring Sciences, Vol. 28, pp.381-389.

Bonnett, M. (2002) 'Education for sustainability as a frame of mind', Environmental Education Research, Vol. 8, No. 1, pp.9-20. 
Braveman, P. (2006) 'Health disparities and health equity: concepts and measurement', Annual Review of Public Health, Vol. 27, pp.167-194.

Bullard, R.D. (1983) 'Solid waste sites and the black Houston community', Sociological Inquiry, Vol. 53, No. 2-3, pp.273-288.

Bullock, H.E. (2008) 'Justifying inequality: a social psychological analysis of beliefs about poverty and the poor', in Lin, A. C. and Harris, D. R. (Eds.): The Colors of Poverty: Why Racial and Ethnic Disparities Persist, Russell Sage Foundation, New York, pp.52-75.

Carson, R. (1962) Silent Spring, Fawcett, Greenwich, CT.

Chircop, A. (2008) 'An ecofeminist conceptual framework to explore gendered environmental health inequities in urban settings and to inform healthy public policy', Nursing Inquiry, Vol. 15 , pp.s135-s147.

Clark, L., Barton, J. A., Brown, N. J., Clark, L., Barton, J. A. and Brown, N. J. (2002) ‘Assessment of community contamination: a critical approach', Public Health Nursing, Vol. 19, pp.354365.

Daily, G. C. (1997) Nature's Services: Societal Dependence on Natural Ecosystems, Washington, Island Press.

De Chiro, G. (1996) 'Nature as community: the convergence of environment and social justice', in Cronon, W. (Ed.): Uncommon Ground: Rethinking the Human Place in Nature, W.W. Norton and Company, pp.298-320.

DeLuca, K. (2007) 'A wilderness environmentalism manifesto: contesting the infinite selfabsorption of humans', in Sandler, R. and Pezzullo, P.C. (Eds.): Environmental Justice and Environmentalism: The Social Justice Challenge to the Environmental Movement. Massachusetts Institute of Technology, Boston, MA, pp.28-55.

Elo, S. and Kyngäs, H. (2008) 'The qualitative content analysis process', Journal of Advanced Nursing, Vol. 62, pp.107-115.

Environmental Protection Agency. (2014) Environmental justice [online]. Washington, D.C.: U.S. Environmental Protection Agency. Available from: http://www.epa.gov/environmentaljustice/ [Accessed 30 June 2014].

Hsieh, H. F. and Shannon, S. E. (2005) 'Three approaches to qualitative content analysis', Qualitative Health Research, Vol. 15, pp.1277-1288.

Hugentobler, M. (2006) 'Man as the measure of all things: a limiting approach to urban regeneration?' New Solutions: A Journal of Environmental and Occupational Health Policy, Vol. 16, No. 4, pp.395-410.

Jones, H. (2009) Equity in development: why it is important and how we can achieve it [online]. Overseas Development Institute. Retrieved from: http://www/odi.org.uk/sites/odi.org.uk/ files/odi-assets/publication-opinion-files/4577.pdf.

Katz, E. and Oechsli, L. (1993) 'Moving beyond anthropocentrism: environmental ethics, development, and the Amazon', Environmental Ethics, Vol. 15, No. 1, pp.49-59.

Krieger, N. (2005) Embodying Inequality: Epidemiologic Perspectives, Baywood Pub, Amityville, NY.

Kroll, G. (2007) Rachel Carson-Silent Spring: a brief history of ecology as a subversive subject. The encyclopedia of Earth: environmental history [online]. Available from: http://www.eoearth.org/view/article/155637/ [Accessed 27 June 2014].

Leopold, A. (1949) A Sand County Almanac and Sketches Here And There, Oxford University Press, New York.

Leopold, A. (1966) 'The land ethic', in Armstrong, S. and Botzler, R.G. (Eds.): 2004. Environmental Ethics: Divergence and Convergence, 3rd ed., McGraw Hill, New York, pp.374-382.

Lovelock, J. (2000) Gaia: A New Look at Life on Earth, 2nd ed., Oxford University, Oxford, UK. 
Middendorf, G., Grant, B., Cubit, J., Love, G., Nilon, C., Peterson, G., Jablonski, L. M. and Poling, T. C. (2003) 'The challenge of environmental justice', Frontiers in Ecology and the Environment, Vol. 1, pp.154-160.

Morello-Frosch, R. and Lopez, R. (2006) 'The riskscape and the color line: examining the role of segregation in environmental health disparities', Environmental Research, Vol. 102, pp.181196.

Naess, A. (1973) 'The shallow and the deep, long-range ecology movement. A summary', Inquiry, Vol. 16, No. 1, 95-100. Available at: http://www.ecology.ethz.ch/education/Readings_stuff/ Naess_1973.pdf.

Nightingale, F. (1970) Notes on Nursing, Brandon/Systems Press, Princeton, NJ.

Orr, D. (2004) Earth in Mind: On Education, Environment and the Human Prospect, 10th Anniversary ed., Island Press, Washington DC.

Rolston III, H. (1991) 'Environmental ethics: values in and duties to the natural world', in Armstrong, S. and Botzler, R.G. (Eds.): 2004. Environmental Ethics: Divergence and Convergence, 3rd ed., McGraw Hill, New York, pp.74-86.

Saha, D. and Paterson, R.G. (2008) 'Local government efforts to promote the "Three E's" of sustainable development', Journal of Planning Education and Research, Vol. 28, pp.21-37.

Sauer, P. (1999) 'Re-inhabiting environmentalism: picking up where Carson and Leopold left off', in Lopez, B. (ed.): 2007. The Future of Nature: Writings on a Human Ecology, Milkweed Editions, New York, pp.5-13.

Sessions, G. (1995) Deep Ecology for the Twenty-first Century, Shambhala Publications, Inc., Massachusetts, USA.

Sirianni, C. and Friedland, L. (2001) Civic Innovation in America, University of California, USA.

Soule, M. E. and Press, D. (1998) 'What is environmental studies?' BioScience, Vol. 48, No. 5, pp.397-405.

United Nations. (1982) World Charter on nature. A/RES/37/7. http://www.un.org/ documents $/$ ga/res/37/a37r007.html. (Accessed 21 July, 2014)

Warren, K. J. (1997) Ecofeminism: Women, Culture, Nature. Indiana University, USA.

Washington, R. O. and Strong, D., (1996) 'A model for teaching environmental justice in a planning curriculum', College of Urban and Public Affairs working papers, 1991-2000, paper 6, pp.1-28.

Wenz, P. (2007) 'Does environmentalism promote injustice for the poor?' in Sandler, R. and Pezzullo, P.C. (Eds.): 2007. Environmental Justice and Environmentalism: the Social Justice Challenge to the Environmental Movement, Massachusetts Institute of Technology, USA, pp.28-55.

White Jr., L.T., (1967) 'The historical roots of our ecologic crisis', in Armstrong, S. and Botzler, R.G. (Eds.): 2004. Environmental Ethics: Divergence and Convergence, 3rd ed., McGraw Hill, New York, pp.219-223.

WHO Commission On The Social Determinants Of Health. (2008) 'Closing the Gap in a Generation: Health Equity Through Action on the Social Determinants of Health, World Health Organization, Geneva, Switzerland.

Wilson, S. M. (2009) 'An ecologic framework to study and address environmental justice and community health issues', Environmental Justice, Vol. 2, pp.15-24.

Zajonc, A. (2006) 'Cognitive-affective connections in teaching and learning: the relationship between love and knowledge', Journal of Cognitive-Affective Learning, Vol. 3, No. 1, pp.1-9. 